\title{
A participação dos estudantes com deficiência física e visual no ensino superior: apontamentos e contribuições das teorias feministas da deficiência
}

\section{The participation of students with physical and visual disabilities in higher education: notes and contributions of feminist theories of disability}

\author{
Marivete Gesser* \\ Adriano Henrique Nuernberg**
}

\begin{abstract}
RESUMO
No cenário de produções acadêmicas, sobre a acessibilidade no ensino superior, tem predominado pesquisas descritivas que mapeiam a realidade e discutem o impacto das políticas públicas atuais nesse contexto. $\mathrm{O}$ objetivo deste texto é fomentar o debate teórico em torno desse tema, visando subsidiar a reflexão conceitual sobre essa realidade, a partir das contribuições das teorias feministas da deficiência. Destacando os conceitos de cuidado e o princípio da interdependência, busca-se promover a ampliação da capacidade de agência dos estudantes em todo o processo educativo. Conclui-se este ensaio apontando para a importância da abordagem crítica da deficiência e do princípio dos direitos humanos como balizadores da inclusão dos estudantes com deficiência no ensino superior.
\end{abstract}

Palavras-chave: Deficiência. Direitos humanos. Participação. Ensino superior.

DOI: $10.1590 / 0104-4060.52925$

* Universidade Federal de Santa Catarina (UFSC). Programa de Pós-Graduação em Psicologia. Florianópolis, Santa Catarina, Brasil. Campus Universitário. Trindade. CEP: 88040-500. E-mail: marivete@yahoo.com.br.

** Universidade Federal de Santa Catarina (UFSC). Núcleo de Estudos sobre Deficiência. Florianópolis, Santa Catarina, Brasil. Campus Universitário. Trindade. CEP: 88040-500. E-mail: adriano.nuernberg@ufsc.br. 


\begin{abstract}
In the scenery of academic production about accessibility in higher education, there is a predominance of descriptive researches that examine the reality and discuss the impact of current public policies in this context. The purpose of this text is to promote the theoretical debate around this theme, aiming to subsidize the conceptual reflection about this reality with the contributions of feminist theories of disability as a starting point. Highlighting the concepts of care and the principle of interdependence, this work pursues the improvement of the capacity of agency of students throughout the whole education process. The conclusion of this essay points out the importance of the critical approach to disability and the principle of human rights as guidelines to include students with disability in higher education.
\end{abstract}

Keywords: Disability. Human rights. Participation. Higher education.

\title{
Introdução
}

Esse texto tem como objetivo propor fundamentos teórico-metodológicos voltados à inclusão de pessoas com deficiência física e visual no ensino superior. Esse recorte se deve à maior proximidade dos autores a esses dois grupos, uma vez que se buscou valorizar as experiências de trabalho na sua articulação com o referencial teórico. Para tanto, primeiramente serão apresentados os principais problemas enfrentados pelas pessoas com deficiência física e visual para o acesso e permanência na universidade. Em seguida, serão apresentados alguns elementos facilitadores para a entrada e a permanência do estudante na universidade. Por fim, buscar-se-á apresentar as contribuições de teorias feministas da deficiência para a promoção da educação inclusiva no ensino superior.

A discussão terá, como pano de fundo, a legislação vigente sobre o tema, a experiência de um dos autores na Coordenadoria de Acessibilidade da Universidade Federal de Santa Catarina (UFSC) - ambos junto ao Núcleo de Estudos sobre Deficiência desta mesma universidade - e o relato de alguns estudantes que têm lesões e impedimentos de natureza física e visual e que vivenciam essa experiência no contexto da UFSC.

A partir da aprovação da Lei de Diretrizes e Bases da Educação Nacional (Lei no 9.394), ressalta-se a importância do tema no cenário brasileiro em que se deliberou que a educação especial deve estar presente em todos os níveis de ensino. Essa é definida pela LDB como "a modalidade de educação escolar, oferecida preferencialmente na rede regular de ensino, para educandos portadores de necessidades especiais" (BRASIL, 1996). 
A inclusão de alunos com deficiência e necessidades educacionais especiais em todos os níveis de ensino é prevista também na Política Nacional de Educação Especial na Perspectiva da Educação Inclusiva conforme a Portaria Ministerial $\mathrm{n}^{\circ} 555$, de 5 de junho de 2007, prorrogada pela Portaria $\mathrm{n}^{\mathrm{o}} 948$, de 09 de outubro de 2007. Esse documento abrange os seguintes pontos: o direito de as pessoas com deficiência terem acesso a níveis de ensino mais elevados; $o$ atendimento educacional especializado; a necessidade de professores formados para o atendimento educacional especializado e demais profissionais da educação para a inclusão escolar; a importância da participação da família e da comunidade; a acessibilidade urbanística, arquitetônica, nos mobiliários e nos equipamentos, nos transportes, na comunicação e informação; e a articulação intersetorial na implementação das políticas públicas.

Na Política Nacional de Educação Especial na Perspectiva da Educação Inclusiva, destaca-se que, na educação superior, a educação especial se efetiva por meio de ações que promovam o acesso, a permanência e a participação dos alunos. Essas ações envolvem o planejamento e a organização de recursos e serviços para a promoção da acessibilidade na questão arquitetônica, nas comunicações, nos sistemas de informação, nos materiais didáticos e pedagógicos. Esses recursos e serviços devem ser disponibilizados nos processos seletivos e no desenvolvimento de todas as atividades que envolvam o ensino, a pesquisa e a extensão. (BRASIL, 2008).

Mais recentemente, no ano de 2015, foi instituída a Lei Brasileira de Inclusão (LBI) (BRASIL, 2015), destinada a assegurar e a promover, em condições de igualdade, o exercício dos direitos e das liberdades fundamentais por pessoa com deficiência, visando à sua inclusão social e a cidadania. Como desdobramento da LBI, foi sancionada, em dezembro de 2016, a Lei $\mathrm{n}^{\circ} 13.409$ (BRASIL, 2016), que dispõe sobre a reserva de vagas para pessoas com deficiência nos cursos técnicos de nível médio e superior das instituições federais de ensino. A soma desses marcadores legais impõe um novo momento de conquistas para os estudantes com deficiência, e de desafios para estes contextos educacionais.

Embora o número de pessoas com deficiência incluídas no ensino comum venha aumentando, ainda são poucas as pessoas com deficiência que tenham acesso ao ensino superior. Em relação àquelas que conseguem acessar, essas enfrentam dificuldades de diferentes ordens para permanecerem e concluírem seus estudos. De 2003 para 2005, houve um crescimento no número de matrículas, de 5.078 para 11.999 alunos, representando um crescimento de 136\% (BRASIL, 2007). Já nos dados do Censo do Ensino Superior de 2013 (INEP, 2014), as matrículas de estudantes com deficiência aumentaram quase 50\% nos últimos quatro anos, sendo a maioria em cursos de graduação presenciais. Em 2013 eram quase 30 mil, enquanto em 2010 eram pouco mais de 19 mil 
estudantes. A maior parte desses estudantes possui algum tipo de deficiência sensorial e/ou física.

De acordo com o art. $1^{\circ}$, da Convenção Sobre os Direitos das Pessoas com Deficiência (2007) - a Convenção da ONU -, "pessoas com deficiência são aquelas que têm impedimentos de natureza física, intelectual ou sensorial, as quais, em interação com diversas barreiras, podem obstruir sua participação plena e efetiva na sociedade com as demais pessoas" (BRASIL, 2011, p. 26).

Portanto, conforme já mencionado, há muitas variações corporais que podem ser vinculadas à experiência de deficiência, tanto em relação aos impedimentos de natureza física quanto visual, que em geral é dividida nos dois grupos básicos de cegueira e baixa visual. As pessoas que vivenciam essas condições enfrentam barreiras que podem obstaculizar seu ingresso, permanência e participação no ensino superior. Esses serão sucintamente apresentadas nos próximos tópicos.

\section{Barreiras na inclusão de estudantes com deficiência física na universidade}

A deficiência física é definida pelo "Decreto da Acessibilidade" (Decreto $n^{\circ}$ 5.296/04) como "alteração completa ou parcial de um ou mais segmentos do corpo humano, acarretando o comprometimento da função física, apresentando-se sob a forma de paraplegia, paraparesia, monoplegia, monoparesia, tetraplegia, tetraparesia, triplegia, triparesia, hemiplegia, hemiparesia, ostomia, amputação ou ausência de membro, paralisia cerebral, nanismo, membros com deformidade congênita ou adquirida, exceto as deformidades estéticas e as que não produzam dificuldades para o desempenho de funções" (BRASIL, 2004).

As pessoas que apresentam lesões e impedimentos corporais se defrontam cotidianamente com muitas barreiras que obstaculizam a participação social na universidade e nos demais espaços sociais. Considerando as diferentes variações corporais caracterizadas como deficiência física, serão apresentadas diversas barreiras enfrentadas pelos estudantes com deficiência.

No que se refere às barreiras arquitetônicas, quando pensamos em ações voltadas à inclusão da pessoa com deficiência física na universidade, não basta propormos como estratégia somente a retirada das barreiras arquitetônicas dentro da universidade. Isso porque o acesso à universidade deve ser pensado desde a residência do aluno com deficiência até à universidade. Portanto, envolve a relação do sujeito com a cidade. 
Nesse aspecto - que aqui caracterizaremos como relacionado ao âmbito macro institucional -, para garantir a inclusão do aluno na universidade, esse poderá precisar de uma moradia adaptada, com acesso fácil à rua, com calçadas adaptadas, transporte acessível; ou seja, que atenda à norma NBR 14022/2009, que regula a acessibilidade no transporte coletivo de passageiros. Portanto, a garantia do acesso dos alunos com deficiência na universidade passa pela construção de uma cidade inclusiva, pautada nas normas técnicas do desenho universal, as quais serão posteriormente explanadas.

Outro aspecto a ser considerado, quando se aborda a inclusão de pessoas com deficiência física na universidade, refere-se ao rompimento da ideia de que esse grupo é constituído necessariamente por cadeirantes. Isso porque existem inúmeras condições de deficiência física que vão exigir da universidade diferentes adaptações em seus espaços. A associação da imagem da pessoa com deficiência com a de um cadeirante pode produzir nos gestores o efeito de que eles vão resolver essa questão alocando salas no andar térreo para os alunos com essa condição, quando na verdade existem muitos tipos de lesões e impedimentos relacionados à deficiência física, pois estes demandam diferentes apoios necessários para a garantia da inclusão e da acessibilidade.

Destaca-se também que não somente o trajeto para se chegar à sala de aula deve estar acessível, mas todo o campus deve fornecer condições para a circulação dessa pessoa com deficiência, que, antes de estudante, é um cidadão. Conforme a Convenção sobre os Direitos da Pessoa com Deficiência preconiza, o cidadão com deficiência deve ter acesso pleno à participação na sociedade da qual a universidade faz parte.

Além das questões anteriormente apresentadas, muitos alunos com deficiência física podem precisar de assistentes pessoais tanto em suas moradias como também no contexto da universidade, uma vez que a falta deste profissional se caracteriza como uma barreira que obstaculiza a autonomia. Um estudante com paralisia cerebral, por exemplo, pode precisar de assistentes pessoais para atividades da vida diária, como alimentação, uso do toalete, deslocamento e comunicação. Essas condições são indispensáveis para que alunos com determinadas condições de deficiência possam participar da universidade em igualdade de condições com os alunos sem deficiência. Esses recursos devem estar presentes no vestibular e no Exame Nacional do Ensino Médio (ENEM/INEP/ MEC), considerando as barreiras para a realização de tais provas - as quais muitas pessoas com deficiência física possuem -, como dificuldade no domínio motor da escrita, presença de dificuldades de controle motor voluntário, que prejudicam a realização prolongada de exames que consideram a funcionalidade e a capacidade de quem não possui nenhum tipo de lesão ou impedimento. 
A diversidade e a complexidade de condições relacionadas à deficiência física demanda das instituições de ensino superior conhecer a condição de cada aluno para definir estratégias de inclusão que favoreçam seu ingresso, permanência e participação. Além disso, aponta para a necessidade, uma vez garantidas as condições de acesso à sala de aula, de que, com base nas especificidades de cada caso, seja propiciado um mobiliário adequado ao conforto dos alunos durante as aulas e outras providências relativas à disponibilização de materiais bibliográficos e sistemas de comunicação suplementar ou alternativa.

Nesse quesito, destaca-se que algumas condições de deficiência vão demandar mobiliário diferenciado, como cadeiras (fixas ou móveis) adequadas às diferentes necessidades de postura corporal, mesas com regulagem de altura e inclinação, tudo voltado à garantia do conforto físico para as atividades acadêmicas. Por exemplo, há condições em que, devido à dificuldade de permanecer sentado por quatro horas seguidas, alguns estudantes podem ter a necessidade de um espaço para que possam se deitar e se esticar com determinada frequência, em decorrência da manutenção da posição sentada em sala de aula produzir muita dor e incorrer em problemas de saúde. Nesse sentido, há necessidade de que na universidade exista uma equipe capacitada para avaliar as necessidades de cada sujeito e supri-las de modo a garantir o conforto físico.

Já no que se refere ao processo de ensino-aprendizagem, algumas condições relacionadas à deficiência física prejudicam as capacidades de comunicação e anotação de informações. Dessa forma, o aluno se encontrará em desvantagem em relação aos demais colegas da turma, tanto no que se refere a tomar nota das informações, como também para realizar as atividades de avaliação caso elas exijam tais capacidades. Para tanto, cabe à universidade prover o suporte adequado em termos de ajudas técnicas e tecnologias assistivas.

Neste tópico, abordamos algumas barreiras vivenciadas pelas pessoas com lesões e impedimentos físicos, as quais podem dificultar o acesso, a permanência e a participação na universidade em igualdade de condições com os alunos sem deficiência. A seguir, apresentaremos as barreiras enfrentadas pelos estudantes com deficiência visual.

\section{Barreiras na inclusão de estudantes com deficiência visual}

A deficiência visual é definida pelo Decreto da Acessibilidade (BRASIL, 2004) como a condição na qual a acuidade visual é igual ou menor que 0,05 no melhor olho, com a melhor correção óptica, e engloba as categorias de cegueira 
e baixa visual. Esta última corresponde à acuidade visual entre 0,3 e 0,05 no melhor olho, com a melhor correção óptica; os casos nos quais a somatória da medida do campo visual em ambos os olhos for igual ou menor que 60 graus; ou a ocorrência simultânea de quaisquer das condições anteriores. Trata-se de um grupo muito diverso, não apenas pela variação funcional, mas também pela diversidade de formas de acessar, registrar o conhecimento e exercer a participação social.

Como já visto na deficiência física, as barreiras para o ingresso no ensino superior estão presentes desde o vestibular. Ainda que boa parte dos concursos vestibulares forneçam as provas em braile ou disponibilizem computadores com programas ledores de tela, nem sempre as especificações, as tecnologias e os recursos de realização das provas atendem às necessidades dos estudantes. É comum, por exemplo, os candidatos que usam braile terem dificuldade de entenderem fórmulas, tabelas e gráficos, transpostas nessa simbologia, ou simplesmente não acessarem a informação visual pela ausência de recursos tecnológicos compatíveis ou de suporte em audiodescrição adequado. As estratégias de acesso e registro do conhecimento do estudante devem ser respeitadas, bem como deve haver rigor técnico no trabalho de transposição das provas em braile, que deverão passar por revisor capacitado para esse tipo de conversão de formato textual.

Para os que superam as barreiras do vestibular, essas mesmas barreiras costumam persistir, a despeito da legislação já obrigar as instituições de ensino superior a garantirem a acessibilidade informacional. Assim, cumpre ressaltar a importância das instituições de ensino superior (IES) disporem de um serviço de conversão dos materiais bibliográficos impressos em formatos acessíveis, como txt, doc, áudio ou mesmo em braile, para que o estudante tenha, no mesmo momento que seus colegas que enxergam, os textos e livros recomendados pelos professores e que são necessários às atividades acadêmicas (BEM et al., 2013).

Além dessas barreiras, existem aquelas relativas à ausência de sinalizações táteis nos pisos e rotas no campus. A necessidade de deslocamento constante do estudante, entre uma atividade acadêmica e outra, para a realização da alimentação e da higiene, demanda um espaço físico que lhe garanta segurança e conforto. O local deve dispor de recursos sonoros, táteis e visuais (contraste para pessoas com baixa visual) que favoreçam a orientação e mobilidade.

De acordo com as especificidades de cada aluno, outros serviços de apoio também serão necessários, como, por exemplo, a cartografia tátil, campo voltado ao estudo das técnicas e recursos que permitem que as pessoas com deficiência visual acessem a mapas e outros recursos de representação visual. Outro exemplo são os testes psicológicos que usam imagens que, na presença de um estudante de psicologia, deverão ser apresentadas de forma que o estudante 
possa compreender os conceitos que favoreçam a relação entre a interpretação do conteúdo visual, e assim poder dialogar com seus colegas e aprender os princípios teóricos desse campo do conhecimento na Psicologia. Para tanto, recursos tecnológicos como lupas eletrônicas, Thermoforming e impressoras 3D são ferramentas importantes para a promoção da acessibilidade informacional.

Os professores deverão ser capacitados a flexibilizarem suas metodologias de ensino que se baseiam na dimensão visual, garantindo o acesso à informação pelos slides, filmes, materiais impressos e uso do quadro negro. Nesse sentido, é fundamental saber noções de como descrever imagens e realizar audiodescrição de vídeos para evitar a dependência total dos monitores e profissionais de suporte em acessibilidade que em geral as universidades dispõem por meio de seus Núcleos de Acessibilidade. O professor não poderá se eximir da responsabilidade em planejar e ministrar suas aulas considerando as necessidades de todos seus alunos, cabendo, assim, introduzir o critério de acessibilidade como parte de seu trabalho docente.

Cabe a todos os ambientes onde circulam os estudantes com deficiência visual se adequarem do ponto de vista da acessibilidade, referendando a NBR $9050 / 2015$. Também aos professores, alunos e demais servidores e funcionários saberem como auxiliar uma pessoa com deficiência visual que solicita alguma ajuda no contexto acadêmico.

\section{Barreiras atitudinais e facilitadores do processo de inclusão}

Um desafio comum dessas duas condições é a existência de fortes barreiras atitudinais que dificultam sua participação no ambiente acadêmico. As barreiras atitudinais, conforme Amaral (2002), são as atitudes, preconceitos, estereótipos e estigmas que estão presentes não só na universidade, mas na educação como um todo, definindo limites e possibilidades e mediando a constituição das subjetividades. Sua existência é uma herança da história de segregação social a que as pessoas com deficiência foram submetidas e que agora começam a ser revertidas pelas conquistas dos movimentos sociais de pessoas com deficiência e pela lenta, mas necessária consolidação da inclusão como um princípio educacional.

De acordo com dados apresentados no Relatório Mundial sobre a Deficiência (2011), as atitudes de professores, administradores escolares, outros estudantes e até membros da família afetam a inclusão de pessoas com deficiência no ensino regular. Com base nos relatos expressos pelos estudantes que são atendidos pela Coordenadoria de Acessibilidade da UFSC, os estudantes com 
deficiência física ainda sofrem com o descrédito social. Esse processo relacionase à generalização indevida, em que o sujeito é reduzido a seus impedimentos e à incapacidade (AMARAL, 2002). Assim, isso produz uma forma de preconceito na qual a pessoa é situada no lugar de menor capacidade, inclusive, do ponto de vista intelectual. Essa questão aponta para a necessidade de se investir na formação de professores e demais profissionais da universidade, visando romper com atitudes que marginalizam pessoas com deficiência.

Com base na condição de deficiência identificada, é necessário disponibilizar ao estudante recursos didáticos e equipamentos especiais para garantir o acesso ao conhecimento e viabilizar a participação dele nas situações vivenciadas no cotidiano da universidade. Dessa forma, o estudante poderá, com autonomia, otimizar suas potencialidades e ter um papel ativo/transformador no ambiente em busca de uma melhor qualidade de vida.

As universidades poderão adotar uma série de medidas que podem facilitar o processo de inclusão de alunos com deficiência física no ensino superior em igualdade de condições às pessoas sem deficiência. Aqui apresentaremos algumas dessas medidas ressaltando que elas devem levar em consideração as especificidades de cada caso.

Um elemento que atua como facilitador da inclusão de pessoas com deficiência física na universidade é a adequação dos espaços às normas do desenho universal que foram incluídas na NBR 9050/2015 da ABNT. Essas normas têm por objetivo garantir a criação de produtos e ambientes para serem usados por todas as pessoas, independente das características pessoais, idade ou habilidades, de modo que esses possam ser alcançados, manipulados e usados independentemente do tamanho do corpo da pessoa, sua postura ou mobilidade.

Ressalta-se que os princípios do desenho universal devem ser incorporados não somente pela universidade, mas também em todos os espaços públicos da cidade. Isso porque, para que o aluno possa não apenas chegar até a universidade, mas também exercer o seu direito de ir e vir, ele precisará de uma cidade acessível. Ademais, conforme Valle e Connor (2014), a partir do modelo social de deficiência, propõe-se o desenho universal ao ensino, que se pauta por princípios, tais como: 1) uso equitativo: o design universal foca a todos, desde a instrução até os recursos; 2) flexibilidade: os métodos de ensino devem partir de diferentes capacidades e funcionalidades; 3 ) instruções simples e intuitivas apoiadas em diferentes recursos como imagens, texto etc.; 4) acessibilidade informacional e comunicacional; 5) tolerância ao erro como oportunidade de aprender; 6) baixo esforço físico: evitar esforço físico desnecessário nas atividades que envolvam mobilidade, orientação, controle motor voluntário; 7) ambiente de aprendizagem comunitário: princípios de convivência solidários e participativos; e 8) clima 
instrucional que valorize a diversidade e projete expectativas positivas para todos os alunos, garantindo feedback no processo e nos resultados.

A Tecnologia Assistiva (TA) também atua como facilitadora do processo de inclusão. Segundo Bersch (2007, p. 31), a tecnologia assistiva consiste em "recursos e serviços que contribuem para proporcionar ou ampliar habilidades funcionais de pessoas com deficiências e, consequentemente, promover vida independente e inclusão". Em suma, são soluções que não devem ser compreendidas apenas em seu aspecto técnico, devendo ser adaptadas ao contexto e à realidade do estudante que se beneficia destas para sua participação na universidade.

A utilização de tecnologias assistivas, por parte das pessoas com deficiência, é compreendida hoje como um dispositivo fundamental para o exercício de sua autonomia. Galvão Filho (2009) demonstra que, mais do que uma questão de usar determinados recursos e artefatos tecnológicos, as tecnologias assistivas referem-se a processos e metodologias que facilitam a vida independente das pessoas com limitações funcionais.

Como exemplo, pode-se citar o uso da bengala para o apoio na orientação e mobilidade por parte de uma pessoa cega. Seu uso, mais do que auxiliar na identificação de obstáculos, envolve uma metodologia complexa de rastreamento, deambulação, exploração de ambientes e garantia da segurança, o que promove a autonomia da pessoa cega no deslocamento físico. Outro exemplo seria o uso de um sistema de comunicação alternativo por parte de uma pessoa com sequelas motoras que afetam a fala. Ao utilizar figuras ou emissores automatizados de mensagens, essa pessoa transforma as condições de interação social, qualificando sua participação social. Por isso, não podemos restringir tais tecnologias aos artefatos físicos em si, mas devemos compreendê-las nos contextos das atividades, processos e funções que elas permitem desenvolver na relação da pessoa com deficiência com o mundo físico e social.

Cumpre destacar que a Convenção da ONU estabelece que a disponibilização deste tipo de recursos é uma obrigação do Estado, reconhecendo-as como um requisito para o exercício pleno dos direitos humanos das pessoas com deficiência, garantindo sua inclusão. Contudo, a utilização da tecnologia assistiva, no momento de provas e exames no ensino superior, ainda é pouco difundida, em razão de sua restrita utilização no meio educacional e dos investimentos financeiros que envolvem o seu uso e manutenção.

Destaca-se ainda que a tecnologia assistiva inclui recursos de comunicação alternativa, de acessibilidade ao computador, de atividades de vida diárias, de orientação e mobilidade, de adequação postural, de adaptação de veículos, órteses e próteses, entre outros. Esses têm por objetivo a resolução de problemas funcionais, com base em uma perspectiva voltada ao desenvolvimento das 
potencialidades humanas, valorização de desejos, habilidades e melhoria da qualidade de vida de modo geral (BRASIL, 2006, p. 18).

A tecnologia assistiva têm por finalidade contribuir para aumentar as capacidades de aprendizagem e interação social do aluno com deficiência física. Por meio dela, é possível a criação de novas alternativas para a comunicação, a escrita, a mobilidade, a leitura e as demais necessidades que ele venha a ter nos contextos de ensino-aprendizagem (BERSCH, 2007). Destaca-se que a escolha das tecnologias adequadas a cada aluno deve ser feita juntamente com ele e com base nas alternativas possíveis para superar as barreiras que limitam a sua inclusão em todos os espaços e momentos da rotina escolar.

As modalidades de tecnologia assistiva que podem vir a ser utilizadas pelos alunos com lesões e impedimentos de natureza física são: auxílios para a vida diária e a vida prática; comunicação aumentativa e alternativa; recursos de acessibilidade ao computador; adequação postural (posicionamento para função); auxílios de mobilidade; sistemas de controle de ambiente e projetos arquitetônicos para acessibilidade. É importante que a universidade disponha de um serviço de apoio aos alunos com deficiência em que cada caso possa ser estudado nas suas especificidades para que sejam escolhidas as tecnologias mais adequadas à garantia das condições de aprendizagem e participação social na sala de aula e nos demais espaços em igualdade de oportunidades.

Outro recurso que pode ser necessário em alguns casos de restrição de mobilidade é a disponibilização de assistentes pessoais aos alunos com deficiência. Esses terão a função de auxiliar nas atividades da vida diária - como ir ao banheiro e alimentar-se -, no deslocamento pelo campus da universidade, no registro de assuntos debatidos em sala de aula, na utilização de dispositivos eletrônicos voltados ao registro de informações e nas demais atividades pedagógicas.

Para que o processo de inclusão de alunos com deficiência seja implementado de modo a garantir o direito à participação na universidade em igualdade de condições, ele deve começar já nos processos seletivos para a graduação (vestibular) e exames de seleção dos programas de pós-graduação. A utilização de um formulário no qual haja um campo para o preenchimento dos recursos que o aluno precisará para realizar a avaliação é de grande relevância. Também há necessidade de se preparar todos os profissionais da universidade para acolher as diferentes necessidades dos alunos.

Por fim, ressalta-se que, embora existam diversos suportes que podem auxiliar no processo de inclusão de pessoas com deficiência física no ensino superior, esses são necessários, mas não suficientes para garantir o acesso e a permanência desses alunos na universidade. Muitas das barreiras vividas no acesso ao conhecimento por parte das pessoas com deficiência são de caráter 
estrutural e institucional e atingem a todos os estudantes. Por isso, entendemos que a melhoria das dimensões pedagógicas, didáticas e curriculares deva caminhar de modo integrado com o incremento constante da acessibilidade. Ademais, também ressaltamos que o avanço na acessibilidade e ao conhecimento leva necessariamente à melhoria dos indicadores de qualidade do ensino. Diante disso, o próximo tópico abordará algumas contribuições da perspectiva feminista da deficiência, com ênfase no princípio da interdependência e na ética do cuidado.

\section{Contribuições da perspectiva feminista da deficiência para a acessibilidade no ensino superior}

A perspectiva feminista da deficiência traz importantes contribuições para a construção de universidades mais inclusivas à diversidade humana. Ela nos convida a pensar importantes questões como o cuidado com o aluno com deficiência, o princípio da interdependência como transversal a todas as relações e a ampliação da capacidade de agência dos estudantes no que se refere a todo o processo educativo.

Kittay (2001) é uma autora estadunidense que tem contribuído para pensar o cuidado a pessoas com deficiência, apontando-o como uma questão de justiça social. Além disso, faz uma crítica a noção de independência como um ideal a ser alcançado nas sociedades modernas e destaca a dependência como um princípio inerente à condição humana, enfatizando o caráter relacional desta condição. Ou seja, ao longo de nossas vidas, seja por ser muito jovem, idoso, doente ou deficiente, precisaremos de cuidados dos outros.

Em um texto escrito por Kittay em colaboração com Jennings e Wassunna, as autoras destacam que há, nas sociedades industrializadas ocidentais, uma negação da dependência humana relacionada com o que elas chamam de "mito do independente", sendo este um sujeito sem corpo, não em desenvolvimento, não doente, não deficiente e que nunca vai envelhecer. Este mito atravessa e constitui nossa maneira de conceber questões de justiça e de política, bem como o valor que damos à dimensão do cuidado (KITTAY; JENNINGS; WASUNNA, 2005).

As autoras citadas atribuem a desvalorização das relações de dependência e do cuidado como relacionada ao fato de estes serem compreendidos como restritos ao âmbito privado (KITTAY; JENNINGS; WASUNNA, 2005), o qual, segundo Tronco (1997), tem sido desvalorizado em relação ao âmbito público. Em nosso cotidiano, ouvimos os estudantes vinculados à Coordenadoria de Acessibilidade da UFSC que indicaram que essa cisão é também reproduzida 
na Educação Superior (âmbito púbico); isso obstaculiza que os professores e demais técnicos da universidade assumam o cuidado do aluno com deficiência.

Outra questão importante para pensar a inclusão dos alunos com deficiência na universidade e a relação deste com o cuidado, abordada por Tronco (1997), refere-se à necessidade de o cuidador ter uma capacidade de atenção indispensável para perceber as necessidades do outro enquanto cuida dele. Para tanto, é preciso conhecer as necessidades alheias, conhecimento que vem dos outros. Não há uma maneira simples de generalizar e deduzir, a partir da própria experiência, o que o outro necessita. Para conhecer as necessidades, é preciso estar atento a elas. (TRONCO, 1997).

Destaca-se que, para que possamos estar atentos às necessidades dos alunos com deficiência na universidade, precisamos fomentar espaços de participação destes não somente na sala de aula, mas em todos os âmbitos da vida acadêmica. Oferecer a oportunidade de participarem ativamente do processo de avaliação para estudar em igualdade de condições com os alunos sem deficiência é um ato político voltado à valorização da humanidade desses alunos, além de ser um desafio das políticas educacionais na implementação dos direitos garantidos pela Convenção sobre os Direitos da Pessoa com Deficiência.

Em relação à ética do cuidado, outra questão que colabora para pensarmos uma universidade inclusiva da variação corporal humana refere-se à necessidade de criticarmos os ideais meritocráticos, os quais negam as diferenças e defendem que todos os sujeitos devem ter as mesmas condições de se desenvolver. Segundo Kittay, Jennings e Wasunna (2005), pessoas que têm a diferença como ponto de partida estarão em desvantagem no acesso às oportunidades. No Brasil, essa questão é amparada pelo artigo $5^{\circ}$, da Constituição Federal (BRASIL, 1988), que se refere ao princípio da equidade e à garantia de que as pessoas em condições de desvantagem tenham acesso a condições voltadas à garantia dessa igualdade. No entanto, ainda há grandes desafios para a consolidação deste direito, uma vez que a garantia de condições diferentes para pessoas que delas necessitam para exercer direitos exige um olhar atento à singularidade de cada sujeito e suas necessidades.

Com base nas reflexões acima, destaca-se que, embora o foco da perspectiva de inclusão no contexto universitário, baseado na ética do cuidado, é o de considerar a dependência como constituinte das relações humanas, destaca-se que precisamos eliminar aquelas dependências que limitam a capacidade de agência do sujeito ${ }^{1}$. Deste modo, um dos grandes desafios para a inclusão de pessoas com deficiência no contexto universitário é o de se fornecer assistência

1 Entende-se aqui agência como uma ação humana capaz tanto de manter as formas sociais de reprodução das estruturas quanto de transformá-las (GIDDENS, 2009). 
quando necessário, sem as tornar dependentes em algo a qual elas não são, uma vez que tal premissa pode corroborar a exclusão dessas pessoas à participação social, bem como diminuir suas possibilidades de desenvolvimento.

No que se refere à questão do cuidado no ensino superior, esse se caracteriza como uma ferramenta para o exercício da autonomia, o que tem necessariamente relação com o acesso ao conhecimento e à participação em igualdade de condições aos alunos sem deficiência. Além disso, esse se sustenta pela importância de prover os recursos necessários para que o aluno exerça o seu direito de escolha. Estas podem ser relacionadas ao direito de escolher as disciplinas que ele quer cursar dentro dos limites regimentais, escolher se quer ou não faltar os $25 \%$ que a legislação permite, manifestar sua opinião nos vários espaços onde isso é possível, circular no Campus da Universidade em igualdade de condições com os alunos sem deficiência. Destaca-se ainda que ele tem direito não somente às necessidades básicas, mas a uma vida independente.

Por fim, destaca-se o enfoque das capacidades proposto por Nussbaum (2007) com base em Amartya Sen, como um dispositivo capaz de ampliar o desenvolvimento e a participação social dos estudantes no ensino superior. Esse enfoque tem como princípio que toda pessoa tem o direito de desenvolver suas capacidades no limite de suas possibilidades. Acredita-se que contribuir com o desenvolvimento das capacidades dos estudantes em todos os níveis de ensino é um ato ético e político, voltado a garantia dos direitos humanos. Assim, promover a acessibilidade é muito mais que uma ação técnica ou instrumental, é fundamental criar as condições para o encontro e a troca entre pessoas de diferentes condições, histórias e potenciais em favor da construção de uma sociedade com mais equidade e acolhimento às diferenças.

\section{REFERÊNCIAS}

AMARAL, L. A. Diferenças, estigma e preconceito: o desafio da inclusão. In: OLIVEIRA, M. K. de. Psicologia, educação e temáticas da vida contemporânea. São Paulo: Moderna, 2002.

ASSOCIAÇÃO BRASILEIRA DE NORMAS TÉCNICAS (ABNT). NBR 14022: acessibilidade em veículos de características urbanas para o transporte coletivo de passageiros. Rio de Janeiro, 2009.

ASSOCIAÇÃO BRASILEIRA DE NORMAS TÉCNICAS (ABNT). NBR 9050: acessibilidade a edificações, mobiliário, espaços e equipamentos urbanos. Rio de Janeiro: 
ABNT, 2015. Disponível em: < http://www.ufpb.br/cia/contents/manuais/abnt-nbr9050-edicao-2015.pdf>. Acesso em: 26 mar. 2017.

BEM, R. M.; NUERNBERG, A. H.; PEREIRA, C. A.; RICHTER, M. O papel da Biblioteca Universitária na vida acadêmica do estudante com deficiência: Ambiente de Acessibilidade Informacional da UFSC. In: AMBONI, N. de F. (Org.). Gestão de bibliotecas universitárias: experiências e projetos da UFSC. 1. ed. Florianópolis: Editora da UFSC, 2013. p. 69-77.

BERSCH, R. Tecnologia Assistiva - TA. In: SCHIRMER, C. R.; BROWNING, N.; BERSCH, R.; MACHADO, R. Atendimento Educacional Especializado: deficiência física. Curitiba: Cromos, 2007. p. 31-37.

BRASIL. Senado Federal. Constituição da República Federativa do Brasil. Brasília, 1988. Disponível em: <http:/www.senado.gov.br/legislacao/const/con1988/ CON1988_05.10.1988/CON1988.pdf>. Acesso em: 15 ago. 2014.

BRASIL. Lei $n^{\circ}$ 9.394, 20 de dezembro de 1996. Lei de Diretrizes e Bases da Educação Nacional.

BRASIL. Presidência da República. Lei $n^{\circ} 13.146$, de 6 de julho de 2015. Disponível em < http://www.planalto.gov.br/ccivil_03/_ato2015-2018/2015/lei/113146.htm>.Acesso em: 15 ago. 2015.

BRASIL. Lei n ${ }^{\circ}$ 13.409, de 28 de dezembro de 2016. Diário Oficial da União, n. 250, p. 03, 2016.

BRASIL. Decreto $n^{\circ}$ 5.296, de 2 de dezembro de 2004. Estabelece normas gerais e critérios básicos para a promoção da acessibilidade das pessoas portadoras de deficiência ou com mobilidade reduzida e dá outras providências. Disponível em: <http://www. planalto.gov.br/CCIVIL- ato2004>. Acesso em: 5 ago. 2014.

BRASIL. Ministério da Educação. Secretaria de Educação Especial. Sala de Recursos Multifuncionais: espaços para o Atendimento Educacional Especializado. Brasília: MEC/SEESP, 2006.

BRASIL. Política Nacional de Educação Especial na Perspectiva da Educação Inclusiva. Brasília: MEC/SEESP, 2008. Disponível em: <http://portal.mec.gov.br/seesp/arquivos/ pdf/politica.pdf $>$. Acesso em: 12 abr. 2012.

BRASIL. Decreto Legislativo $n^{\circ} 186$, de 09 de julho de 2008. Aprova o texto da Convenção sobre os Direitos das Pessoas com Deficiência e de seu Protocolo Facultativo, assinados em Nova Iorque, em 30 de março de 2007. Brasília, DF: Presidência da República. Disponível em: <http://www2.senado.gov.br/bdsf/item/id/99423>. Acesso em: 7 maio 2012.

BRASIL. Presidência da República. Convenção sobre os Direitos das Pessoas com Deficiência (2007). Convenção sobre os Direitos das Pessoas com Deficiência: Protocolo Facultativo à Convenção sobre os Direitos das Pessoas com Deficiência: decreto 
legislativo $\mathrm{n}^{\mathrm{o}} 186$, de 09 de julho de 2008: decreto ${ }^{\circ}$ 6.949, de 25 de agosto de 2009. 4. ed., rev. e atual. - Brasília: Secretaria de Direitos Humanos, Secretaria Nacional de Promoção dos Direitos da Pessoa com Deficiência, 2011.

GALVÃO FILHO, T. A. A Tecnologia Assistiva: de que se trata? In: MACHADO, G. J. C.; SOBRAL, M. N. (Orgs.). Conexões: educação, comunicação, inclusão e interculturalidade. 1. ed. Porto Alegre: Redes Editora, 2009. p. 207-235.

GIDDENS, A. A construção da sociedade. São Paulo: Martins Fontes, 2009.

INSTITUTO NACIONAL DE ESTUDOS E PESQUISAS EDUCACIONAIS ANÍSIO TEIXEIRA (INEP). Censo da educação superior: 2013 - resumo técnico. Brasília: INEP, 2014.

KITTAY, E. F. A feminist public of care meets the new communitarian family policy. Ethics, v. 111, n. 3, p. 523-547, 2001.

KITTAY, E. F.; JENNINGS, B.; WASUNNA, A. A. Dependency, Difference and the Global Ethic of Longterm Care. The Journal of Political Philosophy, v. 13, n. 4, p. 443-469, 2005.

NUSSBAUM, M. C. Las fronteras de la justicia. Madrid: Paidós, 2007. Original publicado em 2006.

ORGANIZAÇÃO MUNDIAL DE SAÚDE. Relatório mundial sobre a deficiência. São Paulo: SEDPcD, 2012.

TRONCO, J. C. Mulheres e cuidados: o que as feministas podem aprender sobre a moralidade a partir disso? In: JAGGAR, A. M.; BORDE, S. R. (Ed.). Genero, corpo e conhecimento. Rio de Janeiro: Record, Rosa dos Tempos, 1997.

VALLE, J. W.; CONNOR, D. J. Ressignificando a deficiência: da abordagem social às práticas inclusivas na escola. São Paulo: Ed: McGraw-Hill, 2014.

Texto recebido em 31 de maio de 2017. Texto aceito em 13 de junho de 2017. 